\title{
HUBUNGAN BUDAYA TERHADAP KESELAMATAN PASIEN UNTUK MENINGKATKAN PELAYANAN KERJA PERAWAT
}

Ade sulistya lubis/181101121

\author{
adesulistyalubis@gmail.com
}

\begin{abstract}
Abstrak
Latar belakang: Membangun budaya keselamatan pasien merupakan langkah awal dalam pengembangan keselamatan pasien. Budaya keselamatan pasien di rumah sakit merupakan bagian dari budaya organisasi, sehingga diperlukan untuk meningkatkan pelayanan kerja perawat. Tujuan : agar dapat mengetahui pentingnya perawatMetode: menggunakan metode tersearch dan analisis dari berbagai sumber seperti buku teks, buku referensi jurnal, e-book, dan juga membandingkan beberapa jurnal yang berhubungan Hubungan budaya terhadap keselamatan pasien untuk meningkatkan pelayanan kerja perawat. Hasil: Keselamatan pasien merupakan inti dari mutu pelayanan kesehatan. Untuk mencapainya, diperlukan komitmen yang kuat dari perawat maupun tim.Kesimpulan: hubungan budaya terhadap keselamatan pasien untuk meningkatkan pelayanan kerja perawat mendukung peningkatan keselamatan dengan aman.
\end{abstract}

\section{Kata kunci: Budaya, keselamatan pasien, perawat.}

Abstract

Background: Building a culture of patient safety is the first step in developing patient safety. The culture of patient safety in hospitals is part of the organizational culture, so it is needed to improve the work services of nurses. Objective: to be able to know the importance of nurses Method: use search methods and analysis from various sources such as textbooks, journal reference books, e-books, and also compare several journals related to cultural relations to patient safety to improve nurse work services. Results: Patient safety is at the core of the quality of health care. To achieve this, a strong commitment from the nurse and team is needed.MConclusion: the cultural relationship to patient safety to improve nurse work services supports safe safety improvement.

Keywords: Culture, patient safety, nurses. 


\section{PENDAHULUAN}

\section{LATAR BELAKANG}

Keselamatan Pasien adalah suatu sistem yang membuat asuhan pasien lebih aman, meliputi asesmen risiko, identifikasi dan pengelolaan risiko pasien, pelaporan dan analisis insiden, kemampuan belajar dari insiden dan tindak lanjutnya, serta implementasi solusi untuk meminimalkan timbulnya risiko dan mencegah terjadinya cedera yang disebabkan oleh kesalahan akibat melaksanakan suatu tindakan atau tidak mengambil tindakan yang seharusnya diambil.

\section{TUJUAN}

Tujuan pembandigan dari beberapa jurnal dan sumber lainnya agar dapat mengetahui Hubungan budaya terhadap keselamatan pasien untuk meningkatkan pelayanan kerja perawat

\section{METODE}

Jurnal ini menggunakan metode tersearch dan analisis dari berbagai sumber seperti buku teks, buku referensi jurnal, e-book, dan juga membandingkan beberapa jurnal yang berhubungan Hubungan budaya terhadap keselamatan pasien untuk meningkatkan pelayanan kerja perawat. Dari analisi berbagai sumber digunakan Untuk mengetahui Hubungan budaya terhadap keselamatan pasien untuk meningkatkan pelayanan kerja perawat. Penulisan jurnal ini dimulai pada tanggal 03 November 2019. Pengolahan jurnal dilakukan dengan metode membandingkan beberapa jurnal yang berhubungan Hubungan budaya terhadap keselamatan pasien untuk meningkatkan pelayanan kerja perawat

\section{HASIL}

Dari jurnal (Iriviranty, Afrisya. 2015. Analisis Budaya Organisasi dan Budaya Keselamatan Pasien Sebagai Langkah Pengembangan Keselamatan Pasien di RSIA Budi Kemuliaan Tahun 2014: Jurnal ARSI/Juni 2015, vol 1 no 3) Menurut WHO, Keselamatan pasien adalah tidak adanya bahaya yang dapat dicegah pada pasien selama proses asuhan kesehatan. Disiplin keselamatan pasien adalah upaya terkoordinasi untuk mencegah kerusakan 
yang terjadi pada pasien, yang disebabkan oleh proses asuhan kesehatan itu sendiri (WHO Patient Safety). Sedangkan definisi keselamatan pasien menurut KKP-RS adalah bebasnya pasien dari harm/cedera yang tidak seharusnya terjadi atau bebas dari hal yang potensial akan terjadi (seperti penyakit, cedera fisik / sosial /psikologis, cacad, kematian, dan lainlain), terkait dengan pelayanan kesehatan (Pedoman Pelaporan Insidens Keselamatan Pasien).

\section{Budaya Keselamatan Pasien}

Menurut The Health Foudation, 2011, budaya keselamatan berkaitan dengan sejauh mana organisasi memprioritaskan dan mendukung peningkatan keselamatan dengan aman. Organisasi dengan budaya keselamatan positif memiliki komunikasi atas dasar saling percaya, persepsi bersama tentang pentingnya keselamatan, keyakinan pada efektivitas langkahlangkah pencegahan, dan dukungan bagi tenaga kerja.

Mengingat masalah keselamatan pasien merupakan masalah yang perlu ditangani segera di fasilitas pelayanan kesehatan di Indonesia maka diperlukan standar keselamatan pasien fasilitas pelayanan kesehatan yang merupakan acuan bagi fasilitas pelayanan kesehatan di Indonesia untuk melaksanakan kegiatannya. Standar Keselamatan Pasien wajib diterapkan fasilitas pelayanan kesehatan dan penilaiannya dilakukan dengan menggunakan Instrumen Akreditasi. Standar keselamatan pasien tersebut terdiri dari tujuh standar yaitu:

1. hak pasien.

2. mendidik pasien dan keluarga.

3. keselamatan pasien dan kesinambungan pelayanan.

4. penggunaan metoda-metoda peningkatan kinerja untuk melakukan evaluasi dan program peningkatan keselamatan pasien.

5. peran kepemimpinan dalam meningkatkan keselamatan pasien.

6. mendidik staf tentang keselamatan pasien.

7. komunikasi merupakan kunci bagi staf untuk mencapai keselamatan pasien.

Dari jurnal (Najihah.2018. Budaya Keselamatan Pasien Dan Insiden Keselamatan Pasien Di Rumah Sakit: Literature Review. Volume 3 Nomor 1, Juli ) Keselamatan pasien dalam pelayanan 
kesehatan mendapatkan banyak perhatian sejak Institute of Medicine (IOM) pada tahun 2000 menerbitkan laporan yang berjudul "To Err is Human : Building a Safer Health System" yang mengemukakan Angka Kematian Akibat KTD pada pasien rawat inap di seluruh Amerika berjumlah 44.000-98.000 orang pertahun. Dengan menggunakan estimasi yang lebih rendah, lebih banyak orang mati akibat kesalahan medis dalam setahun dibandingkan kecelakaan jalan raya, kanker payudara, atau AIDS. Laporan ini disusul dengan publikasi WHO pada tahun 2004 yang menemukan KTD dengan rentang 3,2-16,6\% dari penelitian di berbagai negara (Depkes RI, 2008). Di Indonesia Laporan Insiden Keselamatan Pasien menemukan adanya pelaporan kasus KTD $(14,41 \%)$ dan KNC $(18,53 \%)$ yang disebabkan karena proses atau prosedur klinik $(9,26 \%)$, medikasi (9,26\%), dan Pasien jatuh (5,15\%). (KKP RS, 2011) IOM dalam laporannya tahun 2002 menyatakan jika ada budaya keselamatan pasien dimana efek samping atau resiko dilaporkan tanpa menyalahkan orang-orang, maka orang- orang tersebut memiliki kesempatan untuk belajar dari kesalahan mereka dan memungkinkan untuk melakukan perbaikan untuk mencegah kesalahan yang disebabkan oleh manusia sehingga hal ini dapat mempromosikan keselamatan pasien. (Xuanyue, Yanli, Hao, Pengli, \& Mingming, 2013).

\section{PEMBAHASAN}

Dari jurnal (Najihah.2018. Budaya Keselamatan Pasien Dan Insiden Keselamatan Pasien Di Rumah Sakit: Literature Review. Volume 3 Nomor 1, Juli ) Penerapan budaya keselamatan pasien yang adekuat akan menghasilkan pelayanan keperawatan yang bermutu. Pelayanan kesehatan yang bermutu tidak cukup dinilai dari kelengkapan teknologi, sarana prasarana yang canggih dan petuugas kesehatan yang profesional, namun juga ditinjau dari proses dan hasil pelayanan yang diberikan (Ilyas, 2004). Rumah sakit harus bisa memastikan penerima pelayanan kesehatan terbebas dari resiko pada proses pemberian layanan kesehatan (Cahyono, 2008; Fleming \& Wentzel, 2008). Penerapan keselamatan pasien di rumah sakit dapat mendeteksi resiko yang akan terjadi dan 
meminimalkan dampaknya terhadap pasien dan petugas kesehatan khususnya perawat.

Pelayanan yang aman dan nyaman serta berbiaya rendah merupakan ciri dari perbaikan mutu pelayanan. Perbaikan mutu pelayanan kesehatan dapat dilakukan dengan memperkecil terjadinya kesalahan dalam pemberian layanan kesehatan. Penerapan budaya keselamatan pasien akan mendeteksi kesalahan yang akan dan telah terjadi (Fujita et al., 2013; Hamdan \& Saleem, 2013). Budaya keselamatan pasien tersebut akan meningkatkan kesadaran untuk mencegah error dan melaporkan jika ada kesalahan (Jeffs, Law, \& Baker, 2007). Hal ini dapat memperbaiki outcome yang dihasilkan oleh rumah sakit tersebut.

Menurut Undang-Undang No.44 Tahun 2009, Rumah Sakit adalah institusi pelayanan kesehatan yang menyelenggarakan pelayanan kesehatan perorangan secara paripurna yang menyediakan pelayanan rawat inap,rawat jalan,dan gawat darurat. Sedangkan menurut WHO (World Health Organization), rumah sakit adalah bagian integral dari suatu organisasi sosial dan kesehatan dengan fungsi menyediakan pelayanan paripurna (komprehensif), penyembuhan penyakit (kuratif) dan pencegahan penyakit (preventif) kepada masyarakat.

Keselamatan pasien (patient safety) pada dasarnya merupakan sebuah konsep dalam dunia medis yang terus berkembang. Menurut Rojovsky (2005) keselamatan pasien didefinisikan sebagai upaya maksimal yang dilakukan rumah sakit dalam rangka memberikan pelayanan kepada pasien melalui penerapan metode dan regulasi yang legal serta melalui standar yang terukur untuk meminimalisir kesalahan medis.Berdasarkan Standar Nasional Akreditasi Rumah Sakit (SNARS), terdapat 6 (enam) indikator sasaran kesalamatan pasien. Sasaran Keselamatan Pasien yang wajib diterapkan di semua rumah sakit yang diakreditasi oleh Komisi Akreditasi Rumah Sakit. Penyusunan sasaran ini mengacu kepada Nine Life-Saving Patient Safety Solutions dari WHO Patient Safety (2007) yang digunakan juga oleh Pemerintah. 


\section{KESIMPULAN}

Dengan meningkatnya budaya

keselamatan pasien maka angka kejadian insiden keselamatan pasien dapat diminimalkan. Salah satu upaya yang dapat dilakukan untuk meningkatkan penerapan budaya keselamatan pasien untuk meminimalkan insiden keselamatan pasien adalah dengan melakukan pelaporan insiden keselamatan pasien, baik KNC, KPC, KTC apalagi KTD.

\section{SARAN}

Masih banyak praktisi keperawatan yang mengabaikan pelaporan insiden karena menganggap insiden tersebut masih bisa ditangani dengan sendirinya atau mereka tidak melaporkan jika tidak terjadi cedera pada pasien dan hanya melaporkan jika sudah terjadi cedera. Oleh karena itu, kesadaran tentang budaya keselamatan pasien masih perlu ditingkatkan.

\section{REFERENSI}

Antony, J., F. Antony, and T. Taner. 2006.

The Secret of Success. Public Service Review: Trade and Industry, 10.
Arifin, Alwi, Darmawansyah, dan A.T.S. Ilma S. 2011. Analisis Mutu Pelayanan Kesehatan Ditinjau dari Aspek Input Rumah Sakit di Instalasi Rawat Inap RSU Haji Makassar. Jurnal MKMI, Vol 7 No. 1.

Bandyopadhyay, J. and K. Coppens. 2005. Six Sigma Approach to Healthcare Quality and Productivity Management.

International Journal of Quality \& Productivity Management, Volume 5, No.1. Benedetto, A. R. 2003. Adapting Manufacturing-Based Six Sigma Methodology to the Service Environment of A Radiology Flm Library. Journal of Healthcare Management, 48(4).

Boaden, R. G. 2008. Quality Improvement: Theory and Practice in Healthcare.

Hidayatul Ulumiyah, Nurul. 2018. Meningkatkan Mutu Pelayanan Kesehatan Dengan Penerapan Upaya Keselamatan Pasien Di Puskesmas Jurnal : Jurnal Administrasi Kesehatan 
Indonesia Volume 6 No 2 July-

December Published by

Universitas Airlangga Doi:

10.20473/jaki.v6i2.2018.149155

Iriviranty, Afrisya. 2015. Analisis Budaya

Organisasi dan Budaya

Keselamatan Pasien Sebagai

Langkah Pengembangan

Keselamatan Pasien di RSIA

Budi Kemuliaan Tahun 2014:

Jurnal ARSI/Juni 2015, vol 1

no 3 .

KARS, 2012, Standar akreditasi rumah sakit 6. Dedi, Uus, Fitriyani 2013,

'Analisis Manajemen Mutu

Pelayanan Kesehatan pada

Rumah Sakit Islam Karaw.

Kementerian Kesehatan Republik

Indonesia (2009) Undang-

Undang Republik Indonesia

Nomor 36 Tahun 2009 tentang

Kesehatan. Indonesia

Kementerian Kesehatan Republik

Indonesia (2014) Peraturan

Menteri Kesehatan Republik

Indonesia Nomor 75 Tahun 2014

tentang Pusat Kesehatan

Masyarakat. Indonesia.
R.H.Simamora (2019). Buku ajar pelaksanaaan indentifikasi pasien. Uwais Inspirasi indonesi

R.H. Simamora. (2019). The infiuence of Training handover based SBAR Communication for Improving patients safety. Indian journal of public heath research \& Deveopment

R.H. Simamora (2019). Documentation of Patient Identifikasi Into the hectronic system to improve the quality of nursing serviceec International) journal of soenrifio \& technology tesearch

Simamora, R. H. "Buku Ajar Keselamatan Pasien Melalui Timbang Terima Pasien Berbasis Komunikasi Efektif: SBAR.” (2018).।

Shobirin (2016) 'Hubungan Penerapan Manajemen Puskesmas dan Komitmen Kerja Petugas dengan Mutu Pelayanan Pengobatan di Poli Umum Puskesmas Kabupaten Bangkalan', Jurnal Penelitian Administrasi Publik, 2(2), pp. 513-526. Available 
Stephen P. Robbins, T. A. J. (2008)

Perilaku Organisasi. 12th edn.

Jakarta: Salemba Empat

Sumarni (2017) 'Analisis Implementasi

Patient Safety Terkait

Peningkatan Mutu Pelayanan

Kesehatan di Rumah Sakit',

Jurnal Ners dan Kebidanan

Indonesia,

Ulrich, B. and Kear, T. (2014) 'Patient

Safety and Patient Safety Culture:

Foundations of Excellent Health

Care Delivery.', Nephrology

Nursing Journal.

Undang-Undang Republik Indonesia

Nomor 29 Tahun 2004, Praktek

Kedokteran. 